\title{
Antibacterial and antibiofilm activities of Prangos acaulis Bornm. extract against Streptococcus mutans: an in silico and in vitro study
}

\author{
Mokhtar Nosrati, Mandana Behbahani*, Hassan Mohabatkar, Zahra Shakeran \\ Department of Biotechnology, Faculty of Advanced Sciences and Technologies, University of Isfahan, Isfahan, Iran
}

\section{A R T I C L E I N F O}

Article Type:

Original Article

\section{Article History:}

Received: 10 January 2018

Accepted: 20 June 2018

\section{Keywords:}

Antibacterial activity

Dental caries

In silico analysis

Prangos acaulis

Streptococcus mutans

\begin{abstract}
A B S T R A C T
Introduction: Streptococcus mutans is a principal pathogenic agent in biofilm formation on the teeth surfaces and subsequently development of dental caries and plaque. Therefore, currently introducing novel anti-bacterial and anti-biofilm agents, especially plant based materials are highly regarded. This study was planned to investigate in silico and in vitro antibacterial activities of Prangos acaulis extracts against $S$. mutans in single and biofilm forms and their mutagenicity in Ames test.

Methods: The anti-bacterial and anti-biofilm effects of methanol extracts from various parts of $P$. acaulis were evaluated using disk diffusion and microtiter assay. Moreover, the potential mutagenicity of the extracts was investigated using Ames test. In addition, dominant constitutes of $P$. acaulis that reported in previous studies were subjected to an in silico analysis. The ability of selected phytochemicals to inhibit the glucosyltransferase was evaluated using molecular docking method.

Results: All tested extracts especially root extract had significant antibacterial activity against the single form of $S$. mutans and inhibited biofilm formation without any mutagenic activity. The results also confirmed that three compounds consisting of ar-curcumene, d-limonene and alpha-pinene had strong and appropriate interactions to glucosyltransferase.

Conclusion: This study indicated that $P$. acaulis has potent antibacterial and biofilm inhibition activity against $S$. mutans and can be good candidate for in vitro and in vivo studies with the aim of introducing novel inhibitors of dental caries development.
\end{abstract}

Implication for health policy/practice/research/medical education:

Methanol extracts from different parts of Prangos acaulis showed significant antibacterial activity against the single form of $S$. mutans and inhibited biofilm formation without any mutagenic activity. The extracts showed significance antibacterial and antibiofilm activities against the test microorganism in a dose dependent manner, which could be contributed to ar-curcumene, d-limonene and alpha-pinene. Hence, this plant can be considered as a candidate for preparation of a new drug against microorganisms.

Please cite this paper as: Nosrati M, Behbahani M, Mohabatkar H, Shakeran Z. Antibacterial and antibiofilm activities of Prangos acaulis Bornm. extract against Streptococcus mutans: an in silico and in vitro study. J Herbmed Pharmacol. 2018;7(3):176184. doi: $10.15171 /$ jhp.2018.29.

\section{Introduction}

Dental caries is a multifactorial complication and one of the most common infectious diseases in the world (1). Streptococcus mutans is one of the key factors in development of dental plaque and caries due to the ability for formation of biofilms and colonization on the dental surface in the presence of sucrose. S. mutans has different virulence factors such as mutacins, lactate dehydrogenase $(\mathrm{LDH})$, antigen $\mathrm{B}$, fructosyltransferase (Ftf), non-enzymatic glucan-binding proteins (GBPs) and glucosyltransferases (GTFs) which have vital roles in colonization and accumulation on dental surfaces (2,3). Among the mentioned virulence factors, glucosyltransferase is the key factor in demineralization of the tooth surface, the biofilm formation and development of dental caries. The sticky polymer of sucrose named glucan produced by glucosyltransferase of $S$. mutans is an initiating factor for dental caries formation due to trapping oral bacteria, food debris and salivary components. The secreted acids by trapped bacteria in 
the glucan polymer break down the enamel on the surface of teeth causing dental caries $(4,5)$. Due to key role of the glucosyltransferase in formation and development of dental caries, many studies have been conducted to introduce novel glucosyltransferase inhibitors (6-9). Glucosyltransferase is an enzyme (GTF-SI) encoded by gtf gene, composed of eight chains including A, B, C, D, E, F, G and H. This enzyme plays a key role in biofilm formation and colonization of $S$. mutans on dental surface. The enzyme is a member of glycoside hydrolase family 70 that catalyzes the formation of glucan with different types of glucosidic linkage such as a (1-3), a (1-4) and $\alpha$ (1-6) (10-12). Presently, there is a lot of interest in investigation of natural materials especially plant materials as a good source of new inhibitors for glucosyltransferase of $S$. mutans and prevention of dental caries. Medicinal plants have long been used for prevention and treatment of infectious diseases due to their availability, proper effects, low cost, variety and presence of a wide range of herbal compounds with therapeutic effects (13-19). The genus Prangos that is known Jashir in Iran belongs to Apiaceae family. The plants of this genus are widely used in folk medicine to treat external bleeding, scars of worms, digestive disorders, leukoplakia and infectious diseases as the antimicrobial agent (20). P. acaulis Bornm. is one of the important species of genus Prangos in Iran that is used in folk medicine as Sedative and anti-infective agent $(21,22)$. This plant is used in traditional medicine in some areas of Iran as pain relief and tooth whitener. Therefore, the plant was selected for investigation of the anti-bacterial and anti-biofilm activities against $S$. mutans.

Despite numerous drug properties, plants can include mutagenic compounds (23-25). Therefore, investigation of the mutagenic potential of plant materials is essential. Consequently, along with anti-bacterial properties of the plant extracts probable mutagenicity of them was also evaluated for the first time using Ames test. Designing or screening new drug compounds using conventional methods are costly and time consuming along with possibility of human mistakes. Therefore, in recent years in silico methods for drug discovery and development are highly regarded. Bioinformatics is playing an increasingly key role in drug target identification, drug candidate screening, and refinement as well as characterization of side effects and prediction of drug resistance $(26,27)$. In the present study, the antibacterial and anti-biofilm as well as mutagenicity activity of methanolic extracts from different parts of $P$. acaulis were investigated. Furthermore, in silico analysis was used for screening new inhibitor(s) for glucosyltransferase of $S$. mutans.

\section{Materials and Methods}

In silico analysis

Retrieval of receptor and ligands from database

Fifteen dominant compounds from $P$. acaulis, reported in previous studies $(28,29)$, were selected for in silico analysis (Table 1). The three-dimensional structures of all the phytochemicals and Benzyl penicillin as positive control were retrieved from PubChem database (http://pubchem. ncbi.nlm.nih.gov). Moreover, a three-dimension structure of glucosyltransferase as a receptor was obtained from protein data bank (http://www.rcsb.org) with PDB entry 3AIE.

Receptor and ligands preparation and optimization The raw structure of glucosyltransferase and the ligands were further prepared for in silico analysis. For this aim, the receptor was initially made ready by removing all water molecules and none polar hydrogens, followed by subsequent energy minimization to remove the bad steric clashes using the UCSF Chimera-1.11.2 software. Also, all ligand molecules were minimized in term of energy and structure using ArgusLab 4.01 software.

Table 1. Major constitutes of Prangos acaulis (selected for molecular docking study)

\begin{tabular}{lccc}
\hline Number & Compound & Pubchem CID & Molecular Formula \\
\hline 1 & Alpha-Thujene & 12444324 & 7463 \\
2 & P-Cymene & 6654 & $\mathrm{C}_{10} \mathrm{H}_{16}$ \\
3 & Alpha-Pinene & 6616 & $\mathrm{C}_{10} \mathrm{H}_{14}$ \\
4 & Camphene & 14896 & $\mathrm{C}_{10} \mathrm{H}_{16}$ \\
5 & Beta-Pinene & 31253 & $\mathrm{C}_{10} \mathrm{H}_{16}$ \\
6 & Myrcene & 7462 & $\mathrm{C}_{10} \mathrm{H}_{16}$ \\
7 & Alpha-Terpinene & 440917 & $\mathrm{C}_{10} \mathrm{H}_{16}$ \\
8 & D-Limonene & 92139 & $\mathrm{C}_{10} \mathrm{H}_{16}$ \\
9 & Ar-Curcumene & 5281520 & $\mathrm{C}_{10} \mathrm{H}_{16}$ \\
10 & Alpha-Humulene & $\mathrm{C}_{15} \mathrm{H}_{22}$ \\
11 & 3-ethylidene-2-methyl-1-hexen-4-yne & $\mathrm{C}_{15} \mathrm{H}_{24}$ \\
12 & Germacrene D & $\mathrm{C}_{9} \mathrm{H}_{12}$ \\
13 & Terpineol & $\mathrm{C}_{15} \mathrm{H}_{24}$ \\
15 & Caryophyllene & $\mathrm{C}_{10} \mathrm{H}_{18} \mathrm{O}$ \\
$\mathrm{C}_{15} \mathrm{H}_{24}$ & $\mathrm{C}_{10} \mathrm{H}_{18} \mathrm{O}$ \\
\hline
\end{tabular}


Determination of binding site

The binding site(s) of glucosyltransferase were predicted using MOE software version 2010. The involved amino acids as well as the size of each binding site were also predicted.

Drug-likeness and toxicity prediction

Drug-likeness and safety of each compound must be evaluated to be a candidate as a drug. To calculate the molecular properties associated with drug-likeness (absorption, distribution, metabolism, and elimination) of the ligands SwissADME (http://www.swissadme.ch/index. php) and MedChem Designer 3.0 were used. Moreover, genotoxicity potential of the ligands was predicted using Toxtree 2.6.6 software.

\section{Molecular docking}

The dominant phytochemicals from $P$. acaulis and glucosyltransferase were subjected to ligand-protein docking study. Molecular docking was performed using Autodock4 (version 1.5.6) with the Lamarckian genetic algorithm. Docking parameters which selected for AutoDock4 runs were as follows: 200 docking runs, population size of 200, random starting position and conformation, translation step ranges of $2 \mathrm{~A}$, mutation rate of 0.02 , cross-over rate of 0.8 , local search rate of 0.06 and 2.5 million energy evaluations. Docked conformations were clustered by a tolerance of two $\AA$ root mean square deviations (RMSD).

\section{In vitro analysis}

Plant materials

The fresh plant samples were collected from Kurdistan province of Iran from May to June 2016. The plants were authenticated by a botanist at the herbarium unit of the University of Isfahan, Iran. The plant parts were washed using tap water and then were separated into flower, leaf, stem, seed, and root. Afterward, various parts were air dried in shadow for one week at room temperature, then powdered for extraction.

\section{Preparation of plant extracts}

The methanol extracts of different parts of $P$. acaulis were prepared using maceration method (30). Briefly, 100g of a powdered plant part was soaked in $300 \mathrm{~mL}$ of methanol for 72 hours, then, filtered using Whatman filter paper. The collected extracts were concentrated by rotary vacuum evaporator (Stero glass, Italy) at $45^{\circ} \mathrm{C}$ and then dried using freeze dryer (Zirbus, Germany). All extracts were dissolved in dimethyl sulphoxide (DMSO) and diluted with to give concentrations of 250, 500, 1000, 1500, 2000 and $3000 \mu \mathrm{g} / \mathrm{mL}$.

Microorganisms and culture condition

The tested strains in the study for antibacterial and mutagenicity evaluation of the plant were S. mutans (PTCC 1683) and Salmonella typhimurium TA98 which were respectively purchased from Iranian Biological Resources Center (Tehran, Iran) and Bio Reliance Corporation (Rockville, MD, USA). S. mutans was grown on Nutrient Broth medium at $37^{\circ} \mathrm{C}$ for 8 hours to subculture and prepare for antibacterial analysis. Furthermore, S. typhimurium TA98 was cultured on minimal glucose agar (1.5\% agar, 2.0\% glucose, and 2.0\% Vogel-Bonner medium) containing histidine and biotin at $37^{\circ} \mathrm{C}$ for 18 hours to measure the mutagenic properties of plant materials.

\section{Antibacterial activity}

Antibacterial activity of the $P$. acaulis extracts against the single form of $S$. mutans was investigated using disk diffusion method (31). For this, sterile Whatman filter papers No.1 were prepared and soaked separately in each of the extracts in different concentrations for 5 minutes, then placed on the plate for 24 hours at $37^{\circ} \mathrm{C}$. In the next step, the zone of inhibition around the disc, which indicated antibacterial activity of tested extracts, was measured. In the study, standard discs of penicillin (10 $\mathrm{mg}$ /disk) and DMSO were used as positive and negative controls, respectively.

Furthermore, the minimum inhibitory concentration (MIC) and minimum bactericidal concentration (MBC) values of tested extracts were determined by microdilution method using 96-well microtiter plate (32). For these, $100 \mu \mathrm{L}$ of each extract in tested concentration was added to all wells, which contained $100 \mu \mathrm{L}$ of BHI (Brain Heart Infusion) medium and $20 \mu \mathrm{L}$ of inoculums (containing about $6 \times 10^{4}$ colony) and incubated in $37^{\circ} \mathrm{C}$ for 24 hours. After incubation optical density of each well was read at $620 \mathrm{~nm}$. In the study, a serial dilution of penicillin $(25,50,100,200,400,800,1600$ and $3200 \mu \mathrm{g} /$ $\mathrm{mL}$ ) was considered as positive control. The MIC value was defined as the lowest concentration which inhibited the growth or fewer than three discrete colonies which were detected. Similarly, an MBC value was defined as the lowest concentration of the plant extracts to kill the microorganisms. Plates were read in triplicate, and the average of the MIC and MBC values were recorded.

\section{Inhibition of biofilm formation}

The effects of $P$. acaulis extracts on S. mutans were evaluated using microtiter plate assay (15). For this, the extracts were placed at different concentrations in the wells of a sterile polystyrene microtiter plates, previously treated with Saliva. After this, the microtiter plate wells containing $100 \mu \mathrm{l} \mathrm{BHI}$ medium with $2 \%$ sucrose were inoculated with $3 \mu \mathrm{L}$ of the overnight grown culture of $S$. mutans $(1.0 \times 107$ cells $/ \mathrm{mL}$ in BHI medium $)$, and the samples were incubated at $37^{\circ} \mathrm{C}$ for 18 hours. After incubation, $30 \mu \mathrm{L}$ saline $(0.85 \% \mathrm{NaCl})$ was added to each 
well for removing loosely attached and nonadherent cells. In the next step, the wells were washed three times with sterile distilled water, and the plates were dried for 45 minutes before carrying out biofilm quantification. Biofilm growth and quantification were evaluated using the crystal violet staining method and measuring absorbance at $575 \mathrm{~nm}$. The percentage of inhibition was calculated using the following formula:

Inhibition $(\%)=\left[\left(\mathrm{A}_{575}\right.\right.$ of control- $\mathrm{A}_{575}$ sample $) / \mathrm{A}_{575}$ of control] $\times 100$

\section{Mutagenicity assay}

The mutagenic potential of the extracts was evaluated using Ames test based on mutagenicity in S. typhimurium TA98 with some modifications, as described previously (20). For this, $100 \mu \mathrm{L}$ of an overnight grown culture $\left(10^{7}\right.$ $\mathrm{CFU} / \mathrm{mL}$ ) of the strain was added in sterile screw-capped tubes. Then, $2 \mathrm{~mL}$ of top agar $(0.6 \%$ agar and $0.5 \% \mathrm{NaCl})$ and $100 \mu \mathrm{L}$ of each extract were added to the tubes and vortexed. After this, the solution was poured onto a minimal glucose agar plate and was incubated at $37^{\circ} \mathrm{C}$ for 48 hours. After incubation, numbers of His+ revertant colonies were counted. The positive and negative controls in this assay were sodium azide and sterile distilled water, respectively. The mutagenic effects of tested extracts were estimated using the twofold rule according to the following formula. The substance was considered mutagen if the QM value was calculated higher than two.

$\mathrm{QM}=$ Number of His+ revertant colonies from tested extracts/colonies from negative control
Statistical analysis

The data were obtained in 30 replicates from three separate experiments and were expressed as mean \pm standard deviation (SD) and then analyzed by SPSS V.21 using oneway analysis of variance (ANOVA) and Duncan post hoc tests. Additionally, $P$ values $<0.05$ were considered to be statistically significant between different samples.

\section{Results}

Determination of binding site

The predicted binding sites of glucosyltransferase are presented in Table 2. The results showed that the enzyme has ten binding sites with different amino acid numbers. The size evaluation of predicted binding sits showed that the largest and smallest sits were 161 and $42 \AA$.

Drug-likeness and toxicity prediction

The results of calculation of drug-likeness and toxicity of the ligands are given in Table 3 . The results confirmed that all studied compounds had suitable permeation and distribution with low toxicity. Furthermore, the results showed that the most studied compounds had low gastrointestine absorption except terpineol and nerol that GI absorption was predicted in a high level for them. The results also revealed that among studied compounds only camphene showed genotoxicity potential.

\section{Molecular docking}

The results of molecular docking studies are shown in Table 4. Results revealed that three compounds including ar-curcumene, d-limonene and $\alpha$-pinene had appropriate

Table 2. The predicted binding sites of glucosyltransferase

\begin{tabular}{|c|c|c|}
\hline Active site & Size (Å) & Residues \\
\hline 1 & 161 & $\begin{array}{l}\text { SER244 PHE245 ALA246 ASN249 GLN250 MET297 THR298 TRP299 TRP300 PRO301 ASP302 GLN303 GLN306 LEU330 } \\
\text { ASN333 LEU334 ALA336 GLN337 GLN340 ALA369 TRP370 GLN986 THR990 ALA1058 GLY1059 VAL1061 LEU1062 LYS1063 } \\
\text { ASP1064 GLN1065 TYR1070 PHE1071 PRO1081 LYS1082 SER1083 LEU1084 }\end{array}$ \\
\hline 2 & 101 & $\begin{array}{l}\text { LEU382 TYR430 LEU433 LEU434 ARG475 ASP477 ALA478 ASP480 ASN481 GLU515 TRP517 ARG540 LEU541 LEU544 } \\
\text { HIS587 ASP588 SER589 GLU590 GLN592 ASP593 TYR610 ASN862 PHE907 ASP909 ASN914 TYR916 ALA917 VAL957 } \\
\text { GLN960 TYR962 }\end{array}$ \\
\hline 3 & 140 & $\begin{array}{l}\text { ASP504 ALA573 GLU574 THR575 THR649 ASN650 LYS651 SER652 ARG687 ILE688 VAL691 SER692 GLY693 GLY694 ARG712 } \\
\text { GLY714 LYS715 GLY716 ALA717 LEU718 VAL830 ARG831 VAL832 ALA833 ALA834 SER835 GLN847 ASN848 ALA849 ALA850 } \\
\text { ASP852 SER853 }\end{array}$ \\
\hline 4 & 79 & $\begin{array}{l}\text { ARG585 TYR624 ASN625 LEU628 LEU629 LYS633 THR636 HIS637 TYR638 ASN639 THR64O GLY660 ASP661 THR664 } \\
\text { ASP665 LYS673 THR674 ILE675 ASN676 PRO810 GLN811 }\end{array}$ \\
\hline 5 & 50 & PHE663 GLN668 TYR669 MET670 ALA671 LYS673 TYR677 1YS869 GLU871 GLU872 VAL877 ASN881 LYS884 TRP888 \\
\hline 6 & 62 & ASP263 HIS264 TYR265 LY5394 LEU395 THR396 SER397 GLN398 THR1069 TYR1070 SER1072 LEU1073 VAL1074 ASN1077 \\
\hline 7 & 53 & LEU544 ALA548 LYS549 PRO550 GLU590 ASP593 LEU594 ASP597 LYS633 1Y5634 TYR635 THR636 HIS637 TYR638 \\
\hline 8 & 42 & SER372 GLU375 LEU382 GLN383 LY5384 VAL608 SER611 SER906 ASN1052 ILE1053 LEU1054 GLY1055 \\
\hline 9 & 68 & $\begin{array}{l}\text { GLU681 THR682 LY5685 ALA686 LY5689 TYR690 ARG765 LEU767 TYR778 HI5779 SER780 ASP781 PRO821 GLY823 ALA824 } \\
\text { ALA825 ALA826 }\end{array}$ \\
\hline 10 & 59 & $\begin{array}{l}\text { LYS505 ASN508 ASP509 ARG831 VAL832 ALA833 ALA834 ALA850 LEU851 SER853 ARG854 ALA886 GLY889 VAL890 THR891 } \\
\text { LYS948 GLY949 11E950 LYS951 }\end{array}$ \\
\hline
\end{tabular}


Table 3. The results of calculated drug -likeness and toxicity of dominant constitutes of Prangos acaulis

\begin{tabular}{|c|c|c|c|c|c|c|c|c|c|c|}
\hline Number & $\log P$ & $\log D$ & TPSA & $\log S$ & Gl absorption & $\begin{array}{l}\text { CYP1A2 } \\
\text { inhibitor }\end{array}$ & $\begin{array}{l}\text { CYP2C19 } \\
\text { inhibitor }\end{array}$ & $\begin{array}{l}\text { CYP2C9 } \\
\text { inhibitor }\end{array}$ & $\begin{array}{l}\text { CYP3A4 } \\
\text { inhibitor }\end{array}$ & Genotoxicity \\
\hline 1 & 3.578 & 4.088 & 0 & -2.99 & Low & No & No & No & No & No \\
\hline 2 & 3.562 & 4.090 & 0 & -3.63 & Low & No & No & No & No & No \\
\hline 3 & 4.286 & 4.362 & 0 & -3.51 & Low & No & No & Yes & No & No \\
\hline 4 & 4.285 & 4.131 & 0 & -3.34 & Low & No & No & Yes & No & Yes \\
\hline 5 & 4.286 & 4.152 & 0 & -3.31 & Low & No & No & Yes & No & No \\
\hline 6 & 3.562 & 4.466 & 0 & -3.05 & Low & No & No & No & No & No \\
\hline 7 & 3.267 & 4.710 & 0 & -3.30 & Low & No & No & No & No & No \\
\hline 8 & 3.267 & 4.274 & 0 & -3.50 & Low & No & No & No & No & No \\
\hline 9 & 4.836 & 6.091 & 0 & -4.52 & Low & No & No & No & No & No \\
\hline 10 & 4.534 & 6.110 & 0 & -3.97 & Low & No & No & Yes & No & No \\
\hline 11 & 3.259 & 3.552 & 0 & -2.86 & Low & No & No & No & No & No \\
\hline 12 & 4.534 & 6.010 & 0 & -4.03 & Low & No & No & Yes & No & No \\
\hline 13 & 2.357 & 2.952 & 20.230 & -2.87 & high & No & no & no & no & no \\
\hline 14 & 4.631 & 5.761 & 0 & -3.87 & low & No & no & yes & no & no \\
\hline 15 & 2.642 & 3.190 & 20.230 & -2.78 & high & No & no & no & no & no \\
\hline
\end{tabular}

Table 4. The Results of molecular docking studies on dominant compounds of Prangos acaulis extract and Streptococcus mutans glucosyltransferase

\begin{tabular}{lcc}
\hline Compound & Ki $(\mu \mathrm{M})$ & Gb (kcal/mol) \\
\hline Alpha-Thujene & 276.23 & -3.92 \\
P-Cymene & 244.11 & -3.90 \\
Alpha-Pinene & 84.32 & -5.11 \\
Camphene & 129.21 & -4.21 \\
Beta-Pinene & 124.34 & -4.45 \\
Myrcene & 320.21 & -4.12 \\
Alpha-Terpinene & 188.34 & -3.95 \\
D-Limonene & 3.79 & -4.70 \\
Ar-Curcumene & 4.33 & -5.03 \\
Alpha-Humulene & 92.23 & -4.05 \\
3-ethylidene-2-methyl-1-hexen-4-yne & 146.43 & -2.98 \\
Germacrene D & 170.03 & -3.45 \\
Terpineol & 133.09 & -4.02 \\
Caryophyllene & 143.07 & -4.06 \\
Nerol & 156.88 & -3.55 \\
Penicilin & 3.65 & -4.65 \\
\hline
\end{tabular}

and robust interactions with glucosyltransferase in comparison to penicillin and other tested phytochemicals. The results also confirmed that most of the interactions are van der Waals forces and c-terminal amino acid residues of the enzyme have key roles in enzyme-phytocompounds interactions (Figure 1). Moreover, investigation of amino acids involved in interactions showed that the interactions between penicillin and glucosyltransferase occurred in the predicted cavity number 5 , whilst often interactions of ar-curcumene and $\alpha$-pinene occurred in cavity numbers 2 and 9, respectively, while amino acids involved in the interactions between d-limonene and glucosyltransferase were not in any of the predicted cavities.

Antibacterial activity

The results of the antibacterial activity of $P$. acaulis extracts against S. mutans are shown in Table 5. All tested extracts had antibacterial effects against the tested strain in a dose-dependent manner. Consequently, most antibacterial effects were observed at the highest concentrations. Results also revealed that root extract had the most antibacterial activity followed by flower, leaf, stem and seed extracts. The MIC and MBC values of the tested extract are presented in Table 5. Similarly, to results of disc diffusion assay root and seed extract showed most and least antibacterial activity with MIC values of 5001000 , and 2000-3000 respectively, as well as maximum and minimum $\mathrm{MBC}$ values, were determined for root and seed extract respectively.

Biofilm inhibition activity

The results of potential inhibition of $S$. mutans biofilm formation by $P$. acaulis extracts are shown in Table 6 . The results indicated that all the tested extracts particularly in 2000 to $3000 \mu \mathrm{g} / \mathrm{mL}$ concentrations could inhibit the biofilm formation. Inhibition of the biofilm formation, like the antibacterial effects, was in dose-dependent manner, so that inhibitory function increased with increasing concentration. Results also showed that root and seed extracts had the most and the least efficacies in inhibition of biofilm formation with $66.40 \%$ and $22 \pm 0.20 \%$ reduction, respectively.

\section{Mutagenicity assay}

The results of Ames test for determination of the mutagenic potential of $P$. acaulis extracts are presented in Table 7 . The results confirmed that none of the tested extracts had mutagenic effect in the studied concentrations. Comparative study of tested extracts indicated that the number of His+ revertant colonies caused by the extracts increases with increasing concentrations such that the highest number of the revertant colonies were observed 


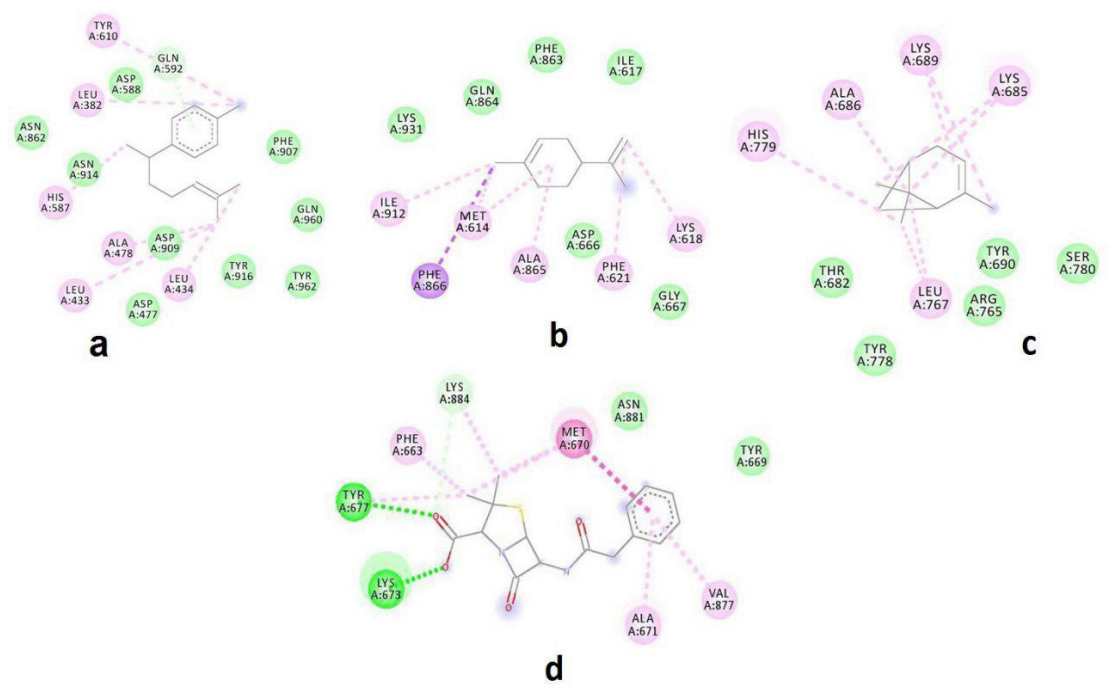

Figure 1. Lowest-energy docking poses of Ar-Curcumene (a), D-Limonene (b), Alpha-Pinene (c) and penicillin (d) with S. mutans glucosyltransferase.

in the highest concentration. Results also showed that root and seed extracts with QM values of $1.67 \pm 0.31$ and $1.33 \pm 0.20$ in highest tested concentration had the most and the least effects on the number of the revertant colonies, respectively

\section{Discussion}

Dental caries is one of the costly diseases, most common preventable and a global oral health problem in the world. Based on the World Health Organization (WHO) report, poor oral health may have a dreadful effect on quality of life and general health. This chronic disease is caused by the interaction of oral microorganisms, diet and some host factors, which among them oral bacteria have a major role in the formation and development of dental caries. Acidic by-products from the bacterial fermentation of dietary carbohydrates are the main cause of the destruction of dental hard tissues that is referred to dental caries (1-3).

About 700 different bacteria species have been identified in the oral cavity. Due to some special abilities of $S$. mutans such as acid production, build up glycogen reserves; synthesize extracellular polysaccharides and adherence to enamel surfaces. It is believed that the bacteria are the key etiological agents in formation and development dental caries (4).

Because of important role of $S$. mutans in dental caries formation, recently, many studies have been conducted to introduce novel anti-microbial agents, especially

Table 5. Antibacterial activity of Prangos acaulis against single form of Streptococcus mutans

\begin{tabular}{|c|c|c|c|c|c|c|c|c|}
\hline \multirow[t]{2}{*}{ Sample } & \multicolumn{8}{|c|}{$\begin{array}{l}\text { Concentration }(\mu \mathrm{g} / \mathrm{mL}) \\
\text { Inhibition zone }(\mathrm{mm})\end{array}$} \\
\hline & $\mathrm{MIC}(\mu \mathrm{g} / \mathrm{mL})$ & $\mathrm{MBC}(\mu \mathrm{g} / \mathrm{mL})$ & 250 & 500 & 1000) & 1500 & 2000 & 3000 \\
\hline Flower & $1000-1500$ & 3000 & - & $6 \pm 0.90$ & $7 \pm 0.45$ & $9 \pm 1$ & $11 \pm 0.25$ & $12 \pm 0.10$ \\
\hline Leaf & $1000-1500$ & 3000 & - & $5 \pm 0.20$ & $6 \pm 0.25$ & $7 \pm 0.65$ & $9 \pm 0.80$ & $11 \pm 0.70$ \\
\hline Stem & $1500-200$ & $>3000$ & - & $5 \pm 0.70$ & $6 \pm 0.60$ & $7 \pm 0.80$ & $9 \pm 0.70$ & $10 \pm 0.20$ \\
\hline Root & $500-1000$ & 2000 & $6 \pm 0.8$ & $8 \pm 0.30$ & $9 \pm 0.10$ & $10 \pm 0.25$ & $12 \pm 0.50$ & $14 \pm 1$ \\
\hline Seed & $2000-3000$ & $>3000$ & - & - & - & $5 \pm 0.40$ & $7 \pm 0.45$ & $8 \pm 0.90$ \\
\hline Penicillin & $200-400$ & 1600 & \multicolumn{6}{|c|}{$19 \pm 0.70$} \\
\hline
\end{tabular}

Table 6. The percentage of inhibition of biofilm structure of Streptococcus mutans

\begin{tabular}{|c|c|c|c|c|c|c|}
\hline \multirow{3}{*}{ Sample } & \multicolumn{6}{|c|}{ Concentration $(\mu \mathrm{g} / \mathrm{mL})$} \\
\hline & \multicolumn{6}{|c|}{ Inhibition (\%) } \\
\hline & 250 & 500 & 1000 & 1500 & 2000 & 3000 \\
\hline Flower & - & $10 \pm 1$ & $14 \pm 3$ & $20 \pm 2$ & $31 \pm 3$ & $48 \pm 1$ \\
\hline Leaf & - & $10 \pm 2.1$ & $12 \pm 1$ & $16 \pm 1$ & $21 \pm 0.30$ & $39 \pm 2$ \\
\hline Stem & - & $8 \pm 1$ & $10 \pm 0.90$ & $13 \pm 3$ & $18 \pm 1$ & $28 \pm 3$ \\
\hline Root & - & $19 \pm 0.75$ & $27 \pm 1$ & $47 \pm 2$ & $59 \pm 2$ & $66 \pm 0.40$ \\
\hline Seed & - & - & - & - & $15 \pm 1$ & $22 \pm 0.20$ \\
\hline
\end{tabular}


Table 7. Mutagenic potential of different extracts from $P$. acaulis (Root and seed extracts showed highest and lowest effects on the number of the revertant colonies, respectively)

\begin{tabular}{lcccccc}
\hline \multirow{2}{*}{ Sample } & \multicolumn{5}{c}{ QM } \\
\cline { 2 - 6 } & $\mathbf{2 5 0}$ & $\mathbf{5 0 0}$ & $\mathbf{1 0 0 0}$ & $\mathbf{1 5 0 0}$ & $\mathbf{2 0 0 0}$ \\
\hline Flower & $1.45 \pm 0.25$ & $1.47 \pm 0.10$ & $1.48 \pm 0.04$ & $1.52 \pm 0.20$ & $1.55 \pm 0.85$ & $1.61 \pm 0.92$ \\
Leaf & $1.30 \pm 0.20$ & $1.32 \pm 0.09$ & $1.36 \pm 0.22$ & $1.39 \pm 0.33$ & $1.45 \pm 0.11$ & $1.53 \pm 0.32$ \\
Stem & $1.18 \pm 0.34$ & $1.20 \pm 0.07$ & $1.24 \pm 0.11$ & $1.26 \pm 0.76$ & $1.31 \pm 0.59$ & $1.36 \pm 0.61$ \\
Root & $1.40 \pm 0.88$ & $1.43 \pm 0.07$ & $1.46 \pm 0.44$ & $1.49 \pm 0.21$ & $1.54 \pm 0.26$ \\
Seed & $1.10 \pm 0.33$ & $1.13 \pm 0.40$ & $1.18 \pm 0.54$ & $1.24 \pm 0.44$ & $1.29 \pm 0.73$ & $1.67 \pm 0.31$ \\
\hline
\end{tabular}

natural materials against various strains (16,33-35). Due to presence of wide range of phytochemicals, lack of side effects and proper effect of medicinal plants in the recent years many attempts have been done to discover and introduce novel antibacterial compounds with emphasizing against $S$. mutans (36-39). The results of this study revealed that methanol extract from different parts of $P$. acaulis especially root extract had significant antibacterial activity against single form of $S$. mutans. Results also showed that all tested extracts could inhibit the biofilm formation in a dose-dependent manner. Our previous studies showed that methanol extracts of Prangos ferulacea and Satureja khuzestanica Jamzad had potent antibacterial activity and inhibited biofilm formation of $S$. mutans (21). Hwang et al confirmed that methanol extract from some medicinal plants including Baeckea frutescens, Glycyrrhiza glabra, Kaempferia pandurata, Physalis angulata and Quercus infectoria had potent antibacterial activities against cariogenic bacterium S. mutans (40). Similarly, Jebashree et al revealed that hexane, ethyl acetate, ethanol and methanol extracts of Psidium guajava, Terminalia chebula, Mimusops elengi and Achyranthes aspera had significant antibacterial activities against $S$. mutans (41). In another study, it was found that aqueous extracts of Sappan lignum, Coptidis rhizoma, and Psoraleae semen effectively inhibited the growth of oral bacteria (42). Also, some studies have been done to evaluate the anti-biofilm activity of medicinal plants. Barnabe and colleagues confirmed antibiofilm activity of obtained extract from Dioscorea altissima and Annona hypoglauca against a single-bacteria biofilm of $S$. mutans (43). The methanol extracts of Camellia japonica and Thuja orientalis were investigated for determining ability to inhibit $S$. mutans biofilm formation. The results showed that the mentioned plants could inhibit the biofilm with an effectiveness of over $90 \%$ (44). In a similar research lee et al revealed that $S$. mutans biofilm had the highest level of sensitivity for the extract of Sophora flavescens (45).

Furthermore, several studies aimed at investigating the anti-bacterial and anti-biofilm activities of pure phytochemicals and some compounds such as linoleic, linolenic, oleanolic, betulinic acids, betulin, beta-sitosterol glucoside and carvacrol introduced as effective compounds against dental caries development and S. mutans biofilm formation $(16,46,47)$. Due to costly and time consuming of convention methods for evaluation, drug likeness and anti-bacterial activities of phytochemicals currently in silico methods have been regarded. Therefore, some studies were planned to in silico screen the effective compounds with anti-biofilm and antibacterial activities $(48,49)$. The results of the present study confirmed that ar-curcumene, d-limonene, and alpha-pinene had strong and appropriate interactions to glucosyltransferase and could be good candidates for inhibiting S. mutans biofilm formation and dental caries development. In this regard, our previous studies showed that some phytochemicals such as carvacrol, $\alpha$-pinen, limonene, gama-terpinen, betabisabolene, gosferol, psoralen and p-cymen were good candidates for investigating the antibacterial activities (20). Similarly, in a structure-based virtual screening study it was revealed that betulin and 3,12-oleandione could inhibit S. mutans glycosyltransferase, efficiently (50). In another structure-based virtual screening study, it was found that quinoxaline derivative could be a good candidate as a potential glucosyltransferase inhibitor (8).

In conclusion, based on the results of the present study $P$. acaulis can be a good candidate for more study and development of a natural anti-dental caries agent.

\section{Conclusion}

This study was planned to in silico and in vitro evaluate the anti-bacterial and anti-biofilm activities of methanol extracts of $P$. acaulis and investigate their potential mutagenicities. The results showed that the extracts especially root extract had significant antibacterial activities against a single form of $S$. mutans. Results also showed that all the extracts could inhibit the biofilm formation in a dose-dependent manner without any mutagenic effects. In silico analysis revealed that arcurcumene, d-Limonene and alpha-Pinene could be good candidates for inhibition of $S$. mutans biofilm formation and development. Therefore, the plant and its by-products might be good candidates for introduction as new drugs.

\section{Acknowledgments}

The authors would like to acknowledge the University of Isfahan for financial support of this study.

\section{Authors' contributions}

All authors contributed to the study. MN and ZSH acquired data. $\mathrm{MN}$ prepared the draft. $\mathrm{HM}$ and $\mathrm{MB}$ 
revised the manuscript for important intellectual content and MN submitted it. All read and confirmed the article ready for publication.

\section{Conflict of interests}

The authors have no conflict of interests relevant to this article.

\section{Ethical approval}

Ethical issues (including plagiarism, misconduct, data fabrication, falsification, double publication or submission, redundancy) have been completely observed by the authors.

\section{Funding/Support}

This study was financially supported by University of Isfahan (Grant No: 922111).

\section{References}

1. Veiga N, Aires D, Douglas F. Dental caries: A review. Journal of Dental and Oral Health. 2016;3(1):2.

2. Selwitz RH, Ismail AI, Pitts NB. Dental caries. Lancet. 2007;369(9555):51-9. doi: 10.1016/s0140-6736(07)60031-2.

3. Yadav K, Prakash S. Dental caries: A microbiological approach. J Clin Infect Dis Pract. 2017;2(1):1-15. doi: 10.4172/2476-213X.1000118.

4. Karpinski TM, Szkaradkiewicz AK. Microbiology of dental caries. J Biol Earth Sci. 2013;3(1):21-4.

5. Nakano YJ, Kuramitsu HK. Mechanism of Streptococcus mutans glucosyltransferases: hybrid-enzyme analysis. J Bacteriol. 1992;174(17):5639-46.

6. Hasan S, Singh K, Danisuddin M, Verma PK, Khan AU. Inhibition of major virulence pathways of Streptococcus mutans by quercitrin and deoxynojirimycin: a synergistic approach of infection control. PLoS One. 2014;9(3):e91736. doi: 10.1371/journal.pone.0091736.

7. Ren Z, Chen L, Li J, Li Y. Inhibition of Streptococcus mutans polysaccharide synthesis by molecules targeting glycosyltransferase activity. J Oral Microbiol. 2016;8:31095. doi: 10.3402/jom.v8.31095.

8. Ren Z, Cui T, Zeng J, Chen L, Zhang W, Xu X, et al. Molecule targeting glucosyltransferase inhibits Streptococcus mutans biofilm formation and virulence. Antimicrob Agents Chemother. 2016;60(1):126-35. doi: 10.1128/aac.00919-15.

9. Veloz JJ, Saavedra N, Alvear M, Zambrano T, Barrientos L, Salazar LA. Polyphenol-rich extract from propolis reduces the expression and activity of Streptococcus mutans glucosyltransferases at subinhibitory concentrations. Biomed Res Int. 2016;2016:4302706. doi: $10.1155 / 2016 / 4302706$.

10. Unligil UM, Rini JM. Glycosyltransferase structure and mechanism. Curr Opin Struct Biol. 2000;10(5):510-7.

11. Breton C, Snajdrova L, Jeanneau C, Koca J, Imberty A. Structures and mechanisms of glycosyltransferases. Glycobiology. 2006;16(2):29r-37r. doi: 10.1093/glycob/ cwj016.

12. Zhu F, Zhang $\mathrm{H}$, Wu H. Glycosyltransferase-mediated sweet modification in oral streptococci. J Dent Res. 2015;94(5):659-65. doi: 10.1177/0022034515574865.
13. Hayacibara MF, Koo H, Rosalen PL, Duarte S, Franco EM, Bowen $\mathrm{WH}$, et al. In vitro and in vivo effects of isolated fractions of Brazilian propolis on caries development. J Ethnopharmacol. 2005;101(1-3):110-5. doi: 10.1016/j. jep.2005.04.001.

14. Kashket S, Paolino VJ, Lewis DA, van Houte J. In-vitro inhibition of glucosyltransferase from the dental plaque bacterium Streptococcus mutans by common beverages and food extracts. Arch Oral Biol. 1985;30(11-12):821-6.

15. Koo H, Pearson SK, Scott-Anne K, Abranches J, Cury JA, Rosalen PL, et al. Effects of apigenin and tt-farnesol on glucosyltransferase activity, biofilm viability and caries development in rats. Oral Microbiol Immunol. 2002;17(6):337-43.

16. Prabu GR, Gnanamani A, Sadulla S. Guaijaverin -- a plant flavonoid as potential antiplaque agent against Streptococcus mutans. J Appl Microbiol. 2006;101(2):48795. doi: 10.1111/j.1365-2672.2006.02912.x.

17. Al-Sohaibani S, Murugan K. Anti-biofilm activity of Salvadora persica on cariogenic isolates of Streptococcus mutans: in vitro and molecular docking studies. Biofouling. 2012;28(1):29-38. doi: 10.1080/08927014.2011.647308.

18. Pinn G. Herbal medicine in infectious disease. Aust Fam Physician. 2001;30(7):681-4.

19. Rios JL, Recio MC. Medicinal plants and antimicrobial activity. J Ethnopharmacol. 2005;100(1-2):80-4. doi: 10.1016/j.jep.2005.04.025.

20. Nosrati M, Behbahani M. In vitro and in silico antibacterial activity of Prangos ferulacea (L.) Lindl and Prangos uloptera Dc, and their mutagenicity in the Ames test. J Microbiol Biotechnol Food Sci. 2016;6(3):930-6.

21. Nosrati M, Behbahani M. The evaluation effect of methanol extracts from Prangos ferulacea and Prangos acaulis on human lymphocytes proliferation and their mutagenicity in Ames test. J Arak Uni Med Sci. 2015;18(97):81-93.

22. Rustaiyan A, Mazloomifar H, Masoudi S, Aghjani Z. Volatile oils of Ducrosia assadii Alava. and Prangos acaulis (DC.) Bornm. from Iran. Journal of Essential Oil Research. 2006;18(6):682-4. doi: 10.1080/10412905.2006.9699205.

23. Reid KA, Maes J, Maes A, van Staden J, De Kimpe N, Mulholland DA, et al. Evaluation of the mutagenic and antimutagenic effects of South African plants. J Ethnopharmacol. 2006;106(1):44-50. doi: 10.1016/j. jep.2005.11.030.

24. Santos FV, Colus IM, Silva MA, Vilegas W, Varanda EA. Assessment of DNA damage by extracts and fractions of Strychnos pseudoquina, a Brazilian medicinal plant with antiulcerogenic activity. Food Chem Toxicol. 2006;44(9):1585-9. doi: 10.1016/j.fct.2006.03.012.

25. Deciga-Campos M, Rivero-Cruz I, Arriaga-Alba M, Castaneda-Corral G, Angeles-Lopez GE, Navarrete A, et al. Acute toxicity and mutagenic activity of Mexican plants used in traditional medicine. J Ethnopharmacol. 2007;110(2):334-42. doi: 10.1016/j.jep.2006.10.001.

26. Searls DB. Using bioinformatics in gene and drug discovery. Drug Discov Today. 2000;5(4):135-43.

27. Xia X. Bioinformatics and drug discovery. Curr Top Med Chem. 2017;17(15):1709-26. doi: 10.2174/15680266176661 61116143440 .

28. Meshkatalsadat MH, Mirzaei HH. Chemical compositions of the essential oils of stems, leaves and flowers of Prangos 
acaulis (Dc) Bornm. Pak J Biol Sci. 2007;10(16):2775-7.

29. Mirzaei HH, Meshkatalsadat $\mathrm{MH}$, Soheilivand S. Determination of essential oil composition of Prangos acaulis (DC) bornm obtained by hydrodistillation and supercritical fluid extraction methods. J Appl Sci. 2007;7(17):2535-8. doi: 10.3923/jas.2007.2535.2538.

30. Azwanida NN. A review on the extraction methods use in medicinal plants, principle, strength and limitation. Med Aromat Plants. 2015;4(196). doi: 10.4172/21670412.1000196.

31. Bauer AW, Kirby WM, Sherris JC, Turck M. Antibiotic susceptibility testing by a standardized single disk method. Am J Clin Pathol. 1966;45(4):493-6.

32. Kang CG, Hah DS, Kim CH, Kim YH, Kim E, Kim JS. Evaluation of antimicrobial activity of the methanol extracts from 8 traditional medicinal plants. Toxicol Res. 2011;27(1):31-6. doi: 10.5487/tr.2011.27.1.031.

33. Smullen J, Koutsou GA, Foster HA, Zumbe A, Storey DM. The antibacterial activity of plant extracts containing polyphenols against Streptococcus mutans. Caries Res. 2007;41(5):342-9. doi: 10.1159/000104791.

34. More G, Tshikalange TE, Lall N, Botha F, Meyer JJ. Antimicrobial activity of medicinal plants against oral microorganisms. J Ethnopharmacol. 2008;119(3):473-7. doi: $\quad 10.1016 /$ j.jep.2008.07.001.

35. Palombo EA. Traditional medicinal plant extracts and natural products with activity against oral bacteria: potential application in the prevention and treatment of oral diseases. Evid Based Complement Alternat Med. 2011;2011:680354. doi: 10.1093/ecam/nep067.

36. Botelho MA, Nogueira NA, Bastos GM, Fonseca SG, Lemos TL, Matos FJ, et al. Antimicrobial activity of the essential oil from Lippia sidoides, carvacrol and thymol against oral pathogens. Braz J Med Biol Res. 2007;40(3):349-56.

37. Almeida LS, Murata RM, Yatsuda R, Dos Santos MH, Nagem TJ, Alencar SM, et al. Antimicrobial activity of Rheedia brasiliensis and 7-epiclusianone against Streptococcus mutans. Phytomedicine. 2008;15(10):886-91. doi: $\quad 10.1016 / \mathrm{j}$.phymed.2007.12.003.

38. Sato M, Fujiwara S, Tsuchiya H, Fujii T, Iinuma M, Tosa H, et al. Flavones with antibacterial activity against cariogenic bacteria. J Ethnopharmacol. 1996;54(2-3):171-6.

39. Sato M, Tanaka H, Fujiwara S, Hirata M, Yamaguchi R, Etoh $\mathrm{H}$, et al. Antibacterial property of isoflavonoids isolated from Erythrina variegata against cariogenic oral bacteria. Phytomedicine. 2003;10(5):427-33. doi: 10.1078/09447113-00225.

40. Hwang JK, Shim JS, Chung JY. Anticariogenic activity of some tropical medicinal plants against Streptococcus mutans. Fitoterapia. 2004;75(6):596-8. doi: 10.1016/j. fitote.2004.05.006.

41. Jebashree HS, Kingsley SJ, Sathish ES, Devapriya D. Antimicrobial activity of few medicinal plants against clinically isolated human cariogenic pathogens-an in vitro study. ISRN Dent. 2011;2011:541421. doi: 10.5402/2011/541421.

42. Yim NH, Jung YP, Cho WK, Kim T, Kim A, Im M, et al. Screening of aqueous extracts of medicinal herbs for antimicrobial activity against oral bacteria. Integr Med Res. 2013;2(1):18-24. doi: 10.1016/j.imr.2013.02.002.

43. Barnabe M, Saraceni CH, Dutra-Correa M, Suffredini IB. The influence of Brazilian plant extracts on Streptococcus mutans biofilm. J Appl Oral Sci. 2014;22(5):366-72.

44. Choi HA, Cheong DE, Lim HD, Kim WH, Ham MH, Oh $\mathrm{MH}$, et al. Antimicrobial and anti-biofilm activities of the methanol extracts of medicinal plants against dental pathogens Streptococcus mutans and Candida albicans. J Microbiol Biotechnol. 2017;27(7):1242-8. doi: 10.4014/ jmb.1701.01026.

45. Lee SH. Antimicrobial effects of herbal extracts on Streptococcus mutans and normal oral streptococci. J Microbiol. 2013;51(4):484-9. doi: 10.1007/s12275-0133312-5.

46. Ramakrishna Y, Goda H, Baliga MS, Munshi AK. Decreasing cariogenic bacteria with a natural, alternative prevention therapy utilizing phytochemistry (plant extracts). J Clin Pediatr Dent. 2011;36(1):55-63.

47. Lall N, Kishore N, Bodiba D, More G, Tshikalange E, Kikuchi H, et al. Alkaloids from aerial parts of Annona senegalensis against Streptococcus mutans. Nat Prod Res. 2017;31(16):1944-7. doi: 10.1080/14786419.2016.1263847.

48. Perveen S, Chaudhary HS. In silico screening of antibacterial compounds from herbal sources against Vibrio cholerae. Pharmacogn Mag. 2015;11(Suppl 4):S5505. doi: 10.4103/0973-1296.172960.

49. Murugan K, Sekar K, Sangeetha S, Ranjitha S, Sohaibani SA. Antibiofilm and quorum sensing inhibitory activity of Achyranthes aspera on cariogenic Streptococcus mutans: an in vitro and in silico study. Pharm Biol. 2013;51(6):728-36. doi: 10.3109/13880209.2013.764330.

50. Murugan K, Sekar K, Sangeetha S, Ranjitha S, Sohaibani SA. In vitro and structure based in silico screening of putative therapeutic quorum sensing inhibitors from an ethanomedicinal herb Achyranthes aspera controlling cariogenic Streptococcus mutans. Pharm Biol. 2013;51(5):728-36. 